\title{
There is No Smoke Without Fire...The Follow-Up Lactic Acidosis in Patient with No Significant Medical History
}

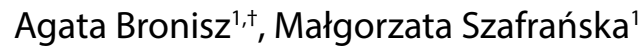

\begin{abstract}
Lactic acidosis is a form of metabolic acidosis with a high anion gap, reduced rate of arterial blood $\mathrm{pH}$ under $7.30 \mathrm{mmol} / \mathrm{l}$, and lactic acid concentration over $5 \mathrm{mmol} / \mathrm{l}$. In the literature, we can find some descriptions of the cases of lactic acidosis in patients with severe systemic diseases (cancer, acquired immunodeficiency syndrome, sepsis, and diabetes with cardiovascular disease and after organ transplantations). Four years ago, we presented the case of lactic acidosis in a patient with no chronic disease - a firefighter where lactic acidosis had developed during a standard exercises test in the smoke chamber. Now we have carried out the evaluation of subsequent patient's follow-up.
\end{abstract}

\section{Keywords}

Lactic acidosis, Etiology, Cancer

\section{Introduction}

Lactic acidosis is defined as metabolic acidosis with a high anion gap (over $16 \mathrm{mmol} / \mathrm{l}$ ), decreased blood $\mathrm{pH}$ under $7.30 \mathrm{mmol} / \mathrm{l}$, bicarbonate concentration under $10 \mathrm{mmol} / \mathrm{l}$ and lactic acid concentration increased above 5 $\mathrm{mmol} / \mathrm{l}$ [1]. A large increase of lactic acid and hydrogen ions can be detected in patients with excessive production of lactic acid or its reduced processing, or both processes simultaneously.

Lactic acidosis is not a specific diabetes complication and is also found in many different chronic diseases and pathological conditions. These include conditions involving hypoxia (lactic acidosis type A), such as hemorrhage, acute and chronic respiratory failure, myocardial infarction complicated by pulmonary edema $[2,3]$. Lactic acidosis can also be caused by diseases and factors occurring in the hypoxia independent mechanisms (lactic acidosis type B), such as liver diseases (poorer use of lactate in the process of gluconeogenesis), renal diseases (metabolic acidosis, accumulation of biguanides), after alcohol intake (increased NADH/NAD+ratio that increases the conversion of pyruvate into lactate), as a side effect of taking in certain drugs like biguanides [4,5]. During the metformin therapy, the increase of lactic acid concentration occurs through two mechanisms. On one hand, the drug increases the production of lactic acid by inhibition of oxidative phosphorylation in mitochondria, which increases the conversion of pyruvate into lactate, during the glycolysis process. On the other hand, it impairs disposal of lactic acid in the liver because it inhibits the production of glucose from lactate in hepatocytes. In patients with type 2 diabetes taking metformin and afflicted by additional conditions, such as impaired kidney or liver function, it may result in developing lactic acidosis $[4,6]$. Clinical symptoms of lactic acidosis are nonspecific, they include: a significant weakness, nausea, vomiting, abdominal pain, diarrhea, shock, cardiac arrhythmias, and impaired consciousness. The symptoms usually appear 


\section{Case Report Agata Bronisz}

suddenly, yet, in some cases they may also arise slowly. On the whole, the general condition of patients is serious, often because of a disease that leads to lactic acidosis. In additional studies we can find moderately increased or normal glucose levels, decreased blood $\mathrm{pH}$, base deficit under $10 \mathrm{mmol} / \mathrm{l}$, an anion gap that may even exceed $25 \mathrm{mmol} / \mathrm{l}$, hyperkalemia. Lactic acidosis may be accompanied by increased concentrations of ketone bodies, and chlorine serum concentration decrease [4]. The treatment of lactic acidosis should include the following procedures: alkalization by an intravenous infusion of sodium bicarbonate $\left(\mathrm{NaHCO}_{3}\right)$, glucose supply together with intravenous insulin administration and causal treatment, including hypotension and shock management, hypoxia and ischemia prevention, sometimes hemodialysis or hemoperfusion. The prognosis in lactate comas is very serious; mortality rate is close to $50 \%$ if the cause of lactic acidosis is a chronic intake of biguanide derivatives [5], and reaches up to $80 \%$ when it is due to some other cause [4].

\section{Case Study}

A 53 year old male (body mass index: 29.1) was admitted to the Department of Endocrinology and Diabetology, Collegium Medicum in Bydgoszcz, Nicolaus Copernicus University in Toruń, due to significant muscle weakness of the lower limbs manifesting in being unable to gain a vertical body position which occurred during intense exercises (mandatory physical fitness training tests for fire brigade employees). During history taking, the patient did not report other diseases or intake of any drugs. Occasionally, he received medical advice from the primary doctor. He smoked about 20 cigarettes a day for 30 years, consumed alcohol 2-3 times a week in an amount of 0.5-1.0 1 of beer, or 50 $\mathrm{ml}$ of $40 \%$ alcohol. He had passed his earlier fire worker routine examinations successfully, the spirometry test results were normal (forced expiratory volume in $1 \mathrm{~s}$ (FEV1) was 3.28 1, i.e. $99 \%$ of the normal value, the ratio of FEV1 to forced vital capacity was $80.6 \%$ ). On admission, the general condition of the patient was assessed as mid-serious. The patient was awake, conscious, with blood pressure (BP) $80 / 60 \mathrm{~mm} \mathrm{Hg}$, tachycardia of $120 / \mathrm{min}$, tachypnea -30 breaths/ min. Auscultation revealed numerous bilateral dry rales, he had a fever up to $38^{\circ} \mathrm{C}$. Laboratory tests performed on admission revealed: metabolic acidosis-pH-6.786 $\mathrm{mmol} / \mathrm{l}$ with acid deficiency $-29.9 \mathrm{mmol} / \mathrm{l}$, anion gap -34.5 $\mathrm{mmol} / \mathrm{l}$, bicarbonate concentration $\left(\mathrm{HCO}_{3}^{-}\right)$ $-4.7 \mathrm{mmol} / \mathrm{l}$ and the carbon dioxide partial pressure (pCO2 ) $-30 \mathrm{~mm} \mathrm{Hg}$; blood glucose $-244 \mathrm{mg} / \mathrm{dl}$, ketonuria $-15 \mathrm{mg} / \mathrm{ml}$, increased levels of lactic acid in the blood serum -26.28 $\mathrm{mmol} / \mathrm{l}$ (normal range: $0.45-2.0$ ) and creatine kinase $-656 \mathrm{U} / \mathrm{l}$ (normal range: 30-200). Serum creatinine, amylase, sodium and potassium levels were within normal limits (respectively: $0.9 \mathrm{mg} / \mathrm{dl}$ (norm: 0.6-1.3), glomerular filtration rate $-94 \mathrm{ml} / \mathrm{min} / 1.73 \mathrm{~m}^{2}$ (norm:>90), amylase - $50 \mathrm{U} / \mathrm{l}$ (norm: 25-125), $\mathrm{Na}^{+}-142.7 \mathrm{mmol} / \mathrm{l}$ (norm: 136-145), $\mathrm{K}+-4.52 \mathrm{mmol} / \mathrm{l}$ (norm: 3.5-4.5). Due to the fact that lactic acidosis may complicate acute coronary syndrome, in the Admission Room acute myocardial ischemia was excluded-electrocardiography within normal limits, markers of myocardial necrosis twice under the cut-off point of acute coronary syndrome. In addition, during hospitalization, a chest X-ray was performed (the result within the norm), and an ultrasound of the abdomen which showed enlarged liver (180 mm length) and its increased echogenicity. No lesions were revealed within its range. To search for the features of hepatic injury, the following laboratory tests were carried out: activity of aspartate aminotransferase -AST -78 U/l (normal range: 4-34) and alanine aminotransferase - $28 \mathrm{U} / 1$ (normal range: 0-45), gamma-glutamyltransferases (GGT) - $154 \mathrm{U} / \mathrm{l}$ (normal range: 12-64) and INR (International Normalized Ratio) was determined -0.94 (normal range: 0.9-1.3). The concentration of total cholesterol was $268 \mathrm{mg} / \mathrm{dl}$ (norm:<200), triglycerides $175 \mathrm{mg} / \mathrm{dl} \quad($ norm:<150). The patient received intravenously $500 \mathrm{ml} \quad 0.9 \%$ sodium chloride and $60 \mathrm{mEq} \mathrm{NaHCO}_{3}$ initially, followed by $1000 \mathrm{ml}$ of $5 \%$ glucose and shortacting insulin administered simultaneously in a pump. In the first hour, a dose of $1 \mathrm{U} / \mathrm{h}$ was used; in the next $5 \mathrm{~h}$ a low flow of $0.5 \mathrm{U} / \mathrm{h}$ was maintained. In addition, the supplementation of potassium chloride was carried out and a low molecular weight heparin in a prevention dose was included. Because of the clinical features of acute bronchitis and slightly increased levels of acute phase proteins $(6.12 \mathrm{mg} / \mathrm{l}$, normal range: 0-5), an empirical antibiotic therapy was included. As a result of the treatment, the patient's general condition rapidly improved. A gradual normalization of acid/base balance was observed. Glycemic profile during intravenous infusion of insulin and $5 \%$ glucose was as follows: 2:30 p.m. $-229 \mathrm{mg} / \mathrm{dl}, 3: 30$ p.m. $-132 \mathrm{mg} /$ dl, 4:30 p.m. $-94 \mathrm{mg} / \mathrm{dl}$, 6:00 p.m. $-102 \mathrm{mg} /$ 
dl, 8:00 p.m. $-82 \mathrm{mg} / \mathrm{dl}, 9: 00$ p.m. $-89 \mathrm{mg} / \mathrm{dl}$. On the second day of hospitalization, the general condition of the patient was assessed as good; $\mathrm{BP}$ was $140 / 80 \mathrm{~mm} \mathrm{Hg}$, heart rate $95 / \mathrm{min}$. The control gasometrical examination showed: $\mathrm{pH}$ $-7.431 \mathrm{mmol} / \mathrm{l}, \mathrm{pCO} 2-29.6 \mathrm{mmHg}$, and base deficit $-3.7 \mathrm{mmol} / 1, \mathrm{HCO}_{3}-19.2 \mathrm{mmol} / \mathrm{l}$. Lactic acid level was $2.6 \mathrm{mmol} / \mathrm{l}$, and fasting plasma glucose $96 \mathrm{mg} / \mathrm{dl}$. The intravenous infusion of insulin and glucose was discontinued. Creatine kinase increased to $11268 \mathrm{U} / \mathrm{l}$. The neurologic consultation revealed no muscle weakness or other abnormalities. During the patient's stay at the clinic, an oral glucose tolerance test with $75 \mathrm{~g}$ glucose (OGTT) was abandoned because of the clinical features of acute bronchitis; however, HbA1c and C-peptide were determined, and the respective values were: $4.9 \%$ (normal range: 4.8-6) and $1.57 \mathrm{mg} / \mathrm{ml}$ (normal range: $1.1-4.4$ ). Six months after discharge, normal carbohydrate metabolism in OGTT test and bilirubin levels within the normal range were found, but AST (52 U/l) was still elevated.

\section{Discussion}

When we presented this case, we were sure that we described the unique case of a healthy man, where excessive physical activity had resulted in metabolic acidosis. So far, all the cases have been reported among people suffering from chronic diseases. In the literature we can find descriptions of lactic acidosis that occurs most frequently in cancer patients, especially of the lymphatic system [7], acquired immunodeficiency syndrome treated with reverse transcriptase inhibitors (3.9/1000) [8-11], diabetes treated with metformin (2-9/100 000) [12-15]. Four years ago we decided to present this case because the fact of severe lactic acidosis occurrence in patients without significant systemic diseases was surprising (to us). We had not found any similar report in all literature available. There was no doubt that in this case, such a large amount of lactic acid was produced during intense exercise the fireman had to make his way through a smoky room while wearing respiratory equipment, and had to perform various tasks (passing through the container, coping with the level difference, opening vertical partitions, moving through the holes, going through a pipe-section, enduring the heat zone). It seemed that the skeletal muscle hypoxia occurred due to substantial disparity between the applied load and the local vascular endurance although the patient had not been treated for any diseases, either cardiovascular or respiratory ones (his spirometry test results were normal). We made sure that the patient had not taken an active part in fire-fighting actions or had not done exercises regularly. In the fire department he had only been charged with office work. We thought that, acute respiratory infection and long-term smoking could have also influenced the rapid growth of lactic acid. The high increase of creatine kinase activity, observed in the subsequent days of hospitalization, clearly indicates the replenishment of energy deficiency in skeletal muscle cells with creatine phosphate reserves within them.

After more than three years we have tried to contact our patient. Unfortunately, it turned out impossible because the patient died. We found out that after a few months a laryngeal cancer had been diagnosed in this patient. Due to persistent dyspnoea and hoarseness, he had sought medical care at the Laryngological Outpatient Clinic and a tumor had been localized on his vocal cords. The histopathological findings had confirmed the presence of neoplastic cells (carcinoma planoepitheliale). Patient had not consented to surgical treatment and after several months he died.

On the basis of the history of our patient, we may conclude that, in case of lactic acidosis in patients without history of serious diseases it should be carefully diagnosed in their detection. 


\section{Case Report Agata Bronisz}

\section{References}

1. Clinical Recommendations of Polish Diabetes Association for the management of patients with diabetes 2018. Clin. Diabetol 4(1), 38 (2018).

2. Clausen SW. Anhydremic acidosis due to lactic acid. Am. J. Dis. Child 29(6), 761-766 (1925).

3. Cohen RD, Woods HF. Clinical and biochemical aspects of lactic acidosis. Oxford: Blackwell. Sci. Publ. 70(1), 294-295 (1976).

4. Holt R, Cockram C, Flyvbjerg A, et al. Textbook of diabetes, $5^{\text {th }}$ edtn. Wiley. Blackwell 534-542 (2017)

5. Sieradzki J. Diabetes mellitus: Polish. 1st edtn. Gdańsk: Via Medica 644-645 (2006).

6. Brown JB, Pedula K, Barzilay J, et al. Lactic acidosis rates in type 2 diabetes. Diabetes. Care 21(1), 1659-1663 (1998),

7. Ruiz JP, Singh AK, Hart P. Type B lactic acidosis secondary to malignancy: Case report, review of published cases, insights into pathogenesis, and prospects for therapy. Sci. World. J 11(1), 1316-1324 (2011).

8. Giola M, Basilico C, Grossi P. Fatal lactic acidosis associated with tenofovir and abacavir. Int. J. Infect. Dis 9(1), 228-229 (2005).

9. Chattha $\mathrm{G}$, Arieff Al, Cummings C. Lactic acidosis complicating the acquired immunodeficiency syndrome. Ann. Intern. Med 118(1), 37-39 (1993).

10. Carr A, Cooper DA. Adverse effects of antiretroviral therapy. Lancet 356(1), 14231430 (2000).

11. Claessens YE, Chiche JD, Mira JP, et al.
Bench-to-bedside review: Severe lactic acidosis in HIV patients treated with nucleoside analogue reverse transcriptase inhibitors. Critic. Care 7(1), 226-232 (2003).

12. Stang M, Wysowski DK, Butler-Jones D. Incidence of lactic acidosis in metformin users. Diabetes. Care 22(1), 925-927 (1999).

13. Biradar V, Moran JL, Peake SL, et al. Metformin-associated lactic acidosis (MALA) Clinical profile and outcomes in patients admitted to the intensive care unit. Crit. Care. Resusc 12(1), 191-195 (2010).

14. Scale T, Harvey JN. Diabetes, metformin and lactic acidosis. Clin. Endocrinol 74(1) 191-196 (2011).

15. Peters N, Jay N, Barraud D, et al. Metforminassociated lactic acidosis in an intensive care unit. Crit. Care 12(1), 1-5 (2008). 